Marquette University

e-Publications@Marquette

7-1-2013

\title{
Situating Moral Justification: Rethinking the Mission of Moral Epistemology
}

Alison Jaggar

University of Colorado - Bolder

Theresa Weynand Tobin

Marquette University, theresa.tobin@marquette.edu

Accepted version. Metaphilosophy, Vol. 44, No. 4 (July 2013): 383-408. DOI. (C) 2013 John Wiley \& Sons, Inc. Used with permission. 
Marquette University

\section{e-Publications@Marquette}

\section{Philosophy Faculty Research and Publications/Department of Philosophy}

This paper is NOT THE PUBLISHED VERSION; but the author's final, peer-reviewed manuscript. The published version may be accessed by following the link in the citation below.

Metaphilosophy, Vol. 44, No. 4 (July, 2013): 383-408. DOI. This article is (C) Wiley and permission has been granted for this version to appear in e-Publications@Marquette. Wiley does not grant permission for this article to be further copied/distributed or hosted elsewhere without the express permission from Wiley.

\section{Contents}

Abstract.

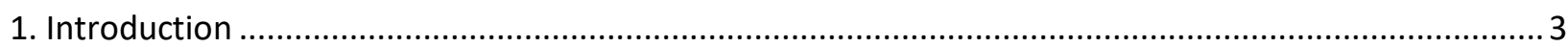

2. A Modern Western Conception of Moral Epistemology ............................................................... 3

3. Assessing Models and Practices of Moral Justification...................................................................... 5

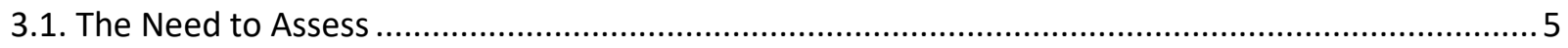

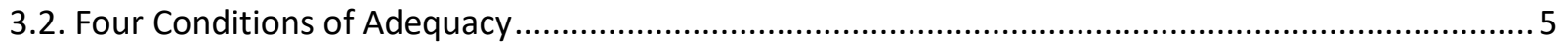

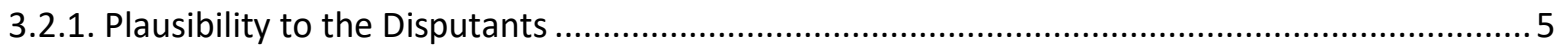

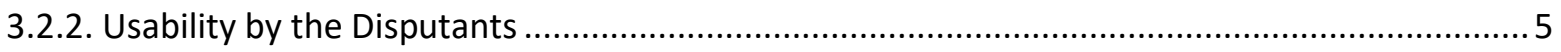

3.2.3. Nonabuse of Power and Vulnerability by Any Disputant .................................................... 6

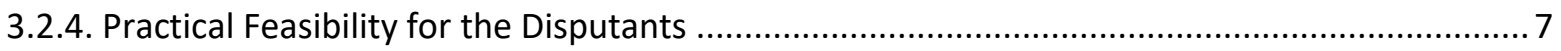

3.2.5. The Sources of Our Adequacy Conditions.......................................................................... 7

3.3. How We Analyze Models and Practices of Reasoning Intended for Moral Justification.................. 7

4. Assessing the Discourse Ethics Model of Moral Justification ............................................................. 8

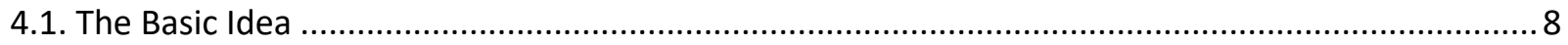

4.2. How Discourse Ethics Delineates the Moral Domain ................................................................. 9

4.3. How Discourse Ethics Characterizes Moral Agents................................................................ 11

4.4. The Method of Moral Reasoning Prescribed by Discourse Ethics ................................................. 11 


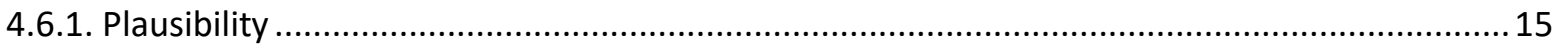

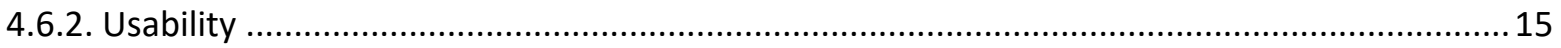

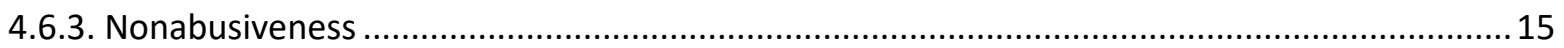

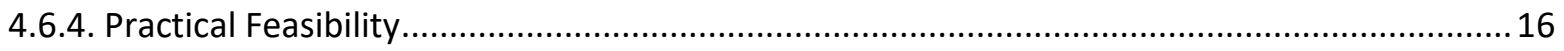

5. The Fundamental Problem: Three Layers of Invidious Idealization.................................................... 16

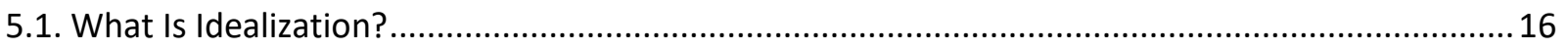

5.2. The Model of Moral Justification Offered by Discourse Ethics Is Invidiously Idealized................... 16

5.3. Discourse Ethics Assumes a Misleadingly Idealized Conception of the Mission of Moral Epistemology.

5.4. Abandoning the Search for the Philosopher's Stone and Rethinking the Mission of Moral

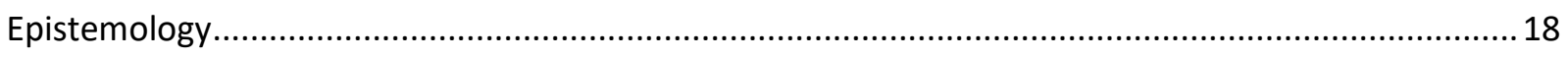

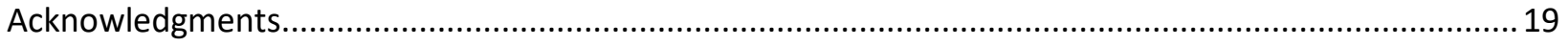

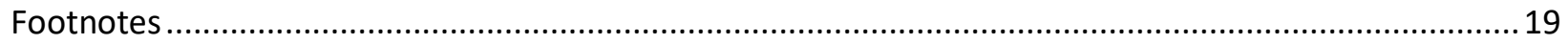

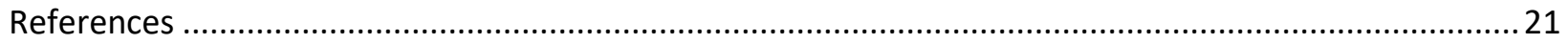

\title{
Situating Moral Justification: Rethinking the Mission of Moral Epistemology
}

\author{
Alison M. Jaggar \\ Department of Philosophy, University of Colorado at Boulder, Boulder, CO \\ Theresa W. Tobin \\ Department of Philosophy, Marquette University, Milwaukee, WI
}

\section{Abstract}

This is the first of two companion articles drawn from a larger project, provisionally entitled Undisciplining Moral Epistemology. The overall goal is to understand how moral claims may be rationally justified in a world characterized by cultural diversity and social inequality. To show why a new approach to moral justification is needed, it is argued that several currently influential philosophical accounts of moral justification lend themselves to rationalizing the moral claims of those with more social power. The present article explains how discourse ethics is flawed just in this way. The article begins by 
identifying several conditions of adequacy for assessing reasoning practices designed to achieve moral justification and shows that, when used in contexts of cultural diversity and social inequality, discourse ethics fails these conditions. It goes on to argue that the failure of discourse ethics is rooted in its reliance on a broader conception of moral epistemology that is invidiously idealized. It concludes by pointing to the need to rethink both the mission and the method of moral epistemology.

\section{Introduction}

This article and its companion piece in this issue of Metaphilosophy, "Naturalizing Moral Justification," are part of our book in progress. The overall aim of the book is to advance philosophical understanding of how moral claims may be justified in contemporary real-world circumstances characterized by cultural and religious diversity and by social inequality. Our work has both critical and constructive aspects. On the critical side, we argue that several prominent philosophical theories of moral justification are flawed because they are idealized in ways that render them susceptible to misuse by those with more social power. We believe that this flaw stems from the theories' shared reliance on an underlying conception of moral epistemology that is also invidiously idealized. On the constructive side, we advocate naturalizing moral epistemology by studying how moral claims are justified in real-world situations of diversity and inequality. We argue that such study can provide philosophers with resources for developing alternative models of moral justification appropriate for varying contexts. Our overall proposal offers an alternative to the search for a one-size-fits-all method of moral justification that is supposed to work in all moral situations.

This first article presents some of our critical work. It begins by outlining the conception of moral epistemology that we later challenge, and it then explains our standards for assessing theoretical models and real-world practices designed to achieve moral justification. We draw on these standards to evaluate critically the model of moral justification advocated by discourse ethics, which provides one philosophical account of moral justification that relies on the conception of moral epistemology that we dispute. At the end of the article, we explain several forms of damaging idealization that infect, respectively, discourse ethics and its underlying epistemological assumptions. We conclude by pointing to the need to rethink both the mission and method of moral epistemology. In our companion article, we explain the new method we recommend for pursuing the new mission.

\section{A Modern Western Conception of Moral Epistemology}

Moral disagreement is a familiar feature of daily life. In Western societies, people frequently disagree with others over issues of public policy, such as immigration, the death penalty, and the supposed right to die, and also over issues of personal conduct, such as whether or not we should be vegetarian or buy only fair trade goods. Often we are able to resolve such disagreements by appealing to shared values, such as the right to life and opposition to cruelty, or by using familiar argumentative strategies such as suggesting that one person try to imagine herself in another's shoes. Some disputes resist resolution, however, because disputants may interpret or weight similar values differently or even appeal to divergent values. It is particularly difficult to reach shared agreement in situations when disagreement is linked with membership in diverse moral communities. One example of such intractable disagreement is the debate over the recent French and Belgian laws banning face coverings in public places. $\stackrel{1}{-}$ Other contemporary examples include: female genital cutting; the Danish cartoons portraying the Prophet as a terrorist; and the controversy over consuming whale meat in the Northern Territories of Canada. 
A central task of moral epistemology is to explain how recalcitrant disputes like these can be addressed rationally and which moral claims are authoritative and why. Historically, moral claims have often been thought authoritative in virtue of their supposedly privileged sources, such as the wisdom of the ancients or the gods or certain sacred practices or texts. Today, Western philosophers usually think that the authority of moral claims is established through using certain privileged models of reasoning, whose use maximizes the probability of producing reliable conclusions (moral methodology). Philosophers also explain why using these models to guide our reasoning confers moral authority on the conclusions we reach (moral epistemology).

When models of moral justification are conceived in this way, they are analogous to philosophers' accounts of scientific methods whose use confers scientific authority on some empirical claims. By definition, relying on scientific methods constitutes what it is to do science. Similarly, reliance on good methods of moral reasoning is constitutive of moral rationality. A moral claim that is justified through good reasoning has rational warrant and is morally authoritative. Some moral epistemologists assert that using their recommended model of moral reasoning enables users to attain the moral point of view. This is an imagined vantage point supposed to provide a uniquely privileged perspective from which moral disagreements may be authoritatively assessed.

Even if a moral claim is justified by good reasoning, this does not entail that it is true in some robust metaphysical sense, just as good scientific reasoning does not always result in empirical truth and sound legal procedures do not always result in convicting the guilty and exonerating the innocent. Yet although good scientific methods and sound legal procedures are fallible, they provide our best means of justifying empirical claims and for determining legal liability. Similarly, our best available moral reasoning provides the most authoritative guide we have for morally appropriate action.

If moral epistemologists' mission is to identify models of reasoning whose use enables reasoners to justify only authoritative moral claims, how can epistemologists accomplish this mission? Contemporary moral philosophers do not expect to derive inspiration from real-world reasoning practices because they view these as susceptible to flaws and fallacies. Instead, they are more likely to pursue their mission through a priori methods, such as reflecting on the necessary and universal conditions of moral reasoning or imagining how moral reasoning would occur in ideal conditions. Sometimes they present fictitious or hypothetical accounts of how moral claims might be justified. In a 2003 interview, Galen Strawson identified a priori arguments as those you can see the truth of "just lying on your couch. You don't have to get up off your couch and go outside and examine the way things are in the physical world. You don't have to do any science."르

This article challenges the idea that the mission of moral epistemology is to identify a uniquely privileged model of moral reasoning enabling those who use it to attain a single authoritative moral point of view. Instead, we contend that people begin from multiple moral starting points and need a variety of methodological strategies or maps in order to reach multiple moral destinations. In our companion article, we challenge the idea that any such projects of epistemological mapping can be performed successfully by solitary philosophers from their armchairs or couches. 


\section{Assessing Models and Practices of Moral Justification}

\subsection{The Need to Assess}

Cultural, religious, and moral communities are characterized by broad agreement among their members on how moral claims should be justified, although members may sometimes disagree about how to interpret and utilize methods of justification that are supposedly shared. When moral disputes occur among communities rather than within them, however, people often disagree more fundamentally about which methods are appropriate for addressing the dispute. In order to address moral disputes in ways that lead to morally rational or authoritative conclusions across as well as within cultural boundaries, it is necessary to find practices of justification that enable people who use them to adjudicate fairly among the various moral perspectives in play without prejudging crucial questions at issue. In situations of diversity and inequality, it is important that all salient perspectives be accorded due respect, rather than be disregarded or repressed, and that processes of moral reasoning be unbiased by social power and privilege. To determine whether or not particular models or practices of moral justification can meet these very general standards when they are employed in real-world contexts, we offer four conditions for assessing them.

\subsection{Four Conditions of Adequacy}

In this section, we explain four conditions for assessing whether particular models and practices of moral reasoning are likely to reach reliable and authoritative conclusions when used in contexts of diversity and inequality. The four conditions work together, building on ideas already familiar in Western moral epistemology. - In our view, a reasoning model or practice that fails any of these conditions when used in a particular context cannot, in this or similar contexts, confer moral authority on the substantive claims that it is intended to support. In such contexts it would not be morally rational to use this model or practice..$^{4}$

\subsubsection{Plausibility to the Disputants}

To justify a normative conclusion is to explain convincingly why it has moral authority. If the authority of moral claims derives from the soundness of the reasoning used to support them, it must be possible to provide an illuminating and plausible metanarrative explaining why using a particular reasoning model or practice tends to produce conclusions that are not morally arbitrary but instead have moral force or weight. We agree with Onora O'Neill that practical reasoning must be intelligible or followable in thought. O'Neill writes, "We fail to reason as soon as we make moves which we hold that others for whom we expect reasons to be cogent cannot follow; we must expect such moves to seem bafflingly arbitrary to those others" $(\underline{1996}, 60)$. We contend that one condition for the adequacy of any reasoning model or practice in a given context of dispute is that it should be possible to tell a story the disputants find plausible that explains why using this reasoning model or practice confers moral authority on the conclusions reached when it is used correctly.

\subsubsection{Usability by the Disputants}

Usability is a second necessary condition of adequacy for any proposed model or practice of moral justification. People involved in moral disputes must not only regard the reasoning practices utilized in addressing the disputes as authoritative, they must also be able to participate in using those practices. If people cannot participate in reasoning about moral claims, they are not acting as full moral agents in situations of justification but merely waiting passively to be told what is right or wrong. The condition of 
usability does not mean that all involved must be able to participate as formal equals. To interpret the condition in this way would violate the first condition because it would rule by fiat that only certain reasoning practices are capable of generating authoritative moral conclusions. Instead, the condition of usability requires that people be able to participate in a way that accords with whatever strategies of justification their communities regard as authoritative. This may require, for example, that participants utilize particular rituals or forms of speech. This interpretation of our usability condition may appear to open the door to domination, but our first and third conditions are designed to block this door.

\subsubsection{Nonabuse of Power and Vulnerability by Any Disputant}

Our third condition for the adequacy of reasoning practices is that they cannot rely on abusing power or vulnerability. It is uncontroversial that physical force is not a strategy for rational persuasion; a normative claim obviously does not gain moral authority because someone is physically bullied into paying lip service to it. Power can also be abused in ways that are less obvious, however, especially where those involved are socially unequal to each other.

All people have a range of characteristics that increase our social power or vulnerability according to the situations in which we find ourselves. Our social vulnerabilities and powers depend on the value or disvalue that prevailing social structures award to these characteristics. Social structures differentiate people's standing based on various characteristics and create differing social possibilities and risks of harm. For instance, although everyone is physically vulnerable to biological infirmity and random hazards, poor people are in addition socially vulnerable because they are deprived of many resources for dealing with life's con tingencies. Social structures create and maintain social powers and vulnerabilities on the basis of a wide range of characteristics such as people's family connections, wealth, caste, religion, educational credentials, nationality, skin color, sex, and age.

Power and vulnerability are abused when people take wrongful advantage of them. Abuses of social power often involve hierarchies, which are socially authorized systems of unequal power and vulnerability. Some hierarchies such as slavery are intrinsically unjust, but social hierarchies can also fulfill a range of legitimate social purposes in institutions such as government, medicine, education, the military, or religion. Although hierarchies are not inherently abusive, the inequalities they create provide opportunities for office holders to abuse their social power by using it for purposes other than those for which it was authorized. For example, scientists may take corporate money to falsify their findings and politicians, priests, teachers, or other officials may extort bribes or sexual favors. Power may be abused even when it arguably makes both parties better off, as in some cases of corruption or exploitation. In unjust hierarchies, most uses of power by those with more privilege are likely to be abusive, but sometimes unjust power may be utilized in nonabusive ways; for instance, unjustly privileged people may use their power to assist people who are vulnerable or even to subvert the system as a whole. Not all hierarchies are formal, based in institutions with legal force; many are informal or inexplicit. This allows another type of power abuse to occur when informal power is used to subvert situations in which participants are formally equal, such as when bribery or social connections are used to influence supposedly meritocratic decisions about allocating educational positions or jobs. Abuses of social power may often be unintentional rather than deliberate, since superior social power and privilege are frequently invisible to those who possess them.

In contexts of moral justification, abuse occurs when some disputants take wrongful advantage of their own power or others' vulnerability to discredit the views of others and make their own views appear 
unduly credible. This can happen in innumerable ways short of overt physical coercion. Abuse includes but is not limited to: misrepresentation or selective presentation of evidence, distortion, intimidation, logical trickery, mystification, ridicule, disregard, and refusal to understand. It also occurs when some disputants insist on a particular style of argumentation in which others are unskilled or uncomfortable or on using a vocabulary that does not fit well with the moral concepts of some disputants or is inadequate to express their perspectives.

\subsubsection{Practical Feasibility for the Disputants}

We noted earlier that our condition of plausibility resembles O'Neill's requirement that practical reasoning must be intelligible or followable in thought. O'Neill also specifies a second type of followability, namely, that practical reasoning can advocate only proposals that are followable in the sense of being real possibilities for action in the relevant sphere. She writes, "Proposals for action will therefore not be reasoned unless they are not only intelligible, but real possibilities for those who are to be offered reasons for certain recommendations or prescriptions, warnings or proscriptions. ... We cannot give others reason for adopting principles which we do not think they could adopt" $(1996,57-$ 58). We take our lead from O'Neill in contending that no model or practice of moral justification can be rational in a given context if it prescribes a course of action that is not feasible or realistically possible for some people in the situation.

\subsubsection{The Sources of Our Adequacy Conditions}

Our conditions for assessing models and practices of justification are intended to provide a more detailed elaboration of our basic-and we think uncontroversial-assumption about moral justification, namely, that no reasoning practice confers moral authority in a given context if it is initially biased against any of those involved or their views. We stipulate the condition of plausibility because it is an essential condition of explanation in any field; a moral claim cannot be justified for any individual or group unless it is based on reasoning whose moral force they recognize. We stipulate the condition of usability because moral claims cannot be justified for people who are unable to participate in the reasoning used to support them. We stipulate that practices which depend on abusing vulnerability or power cannot confer moral authority on any substantive conclusions, because rationality of all kinds is widely contrasted with abusing power. - Finally, our acceptance of the belief that "ought" implies "can" explains our stipulation that a practice of justification is not rational in a given context unless it recommends courses of action that are realistically possible for all of those involved.

\subsection{How We Analyze Models and Practices of Reasoning Intended for Moral Justification}

We use the four conditions above to assess both philosophical models proposed by several prominent moral philosophers and actual practices of moral justification used by nonphilosophers in some realworld moral disputes. Our critical appraisals focus on four interrelated aspects of philosophical models and real-world reasoning practices.

First, we look at the way a particular model or practice delineates the moral domain. Philosophical models of moral justification offer general maps of the sphere of morality and explain why they draw the boundaries in one place rather than another; for instance, they typically separate morality from convention, law, theology, and anthropology and explain why they differentiate among these. People engaged in real-world disputes also delineate a moral domain by the way that they frame the issues at 
stake. For example, people disputing whale or seal hunting may frame the disputes as issues of cultural colonization, resistance, and survival, as issues of animal cruelty, or as issues of species preservation or ecological balance. To assess the ways in which models or practices of moral justification enable people to delineate the moral domain, we ask how they allow them to identify and interpret the moral issues at hand.

Second, we look at how particular models and practices enable people to characterize moral agency. Within processes of justification, people (or other beings) might have moral standing in more than one way. They may participate as moral agents, whose voice is recognized in processes of justification; they may participate as informants providing testimony whose moral import is assessed by others; or they may be viewed simply as moral objects, beings of moral concern with a stake but not a legitimate voice in justificatory processes. For instance, children or even some cognitively disabled people may be regarded as informants, while battery chickens may be regarded merely as objects of moral concern.

Third, we analyze the methods of reasoning proposed by philosophical models or utilized in real-world practices. Which methods are recommended or permitted and which are rejected as illegitimate? What considerations may count as reasons or evidence, which are ruled inadmissible, and what are warranted inference patterns? We assess these, too, by reference to our four conditions.

Finally, we consider the practical outcomes justified by using various models or practices of justification. When assessing a proposed philosophical model, we can only look at the general sorts of recommendations for action that it is likely to generate in circumstances of diversity and inequality. When we study real-world cases, we are able to assess actual recommendations for action that are generated by using particular reasoning practices in particular contexts. In assessing practical recommendations for action, the condition of feasibility is especially salient.

Even when the four conditions are accepted in principle, it is always possible for people to disagree about how to apply them in specific contexts. None of our conditions can be deployed mechanically, and, as we invoke them to assess the use of particular reasoning strategies, we offer arguments about what should count in particular contexts as plausibility, usability, power abuse, and practical feasibility. We recognize, however, that our arguments are challengeable. In any given context of moral justification, it will be possible to dispute whether or not a particular model or practice of justification truly is plausible, usable, abusive, or practically feasible.

In this article, we use the conditions to assess the model of moral justification proposed in Jürgen Habermas's version of discourse or communicative ethics (Habermas $\underline{1990}$ ).

\section{Assessing the Discourse Ethics Model of Moral Justification}

\subsection{The Basic Idea}

Discourse ethics is a proceduralist theory of justification which advocates that the authority of moral claims should be evaluated not directly by reference to their content but instead by reference to the reasoning through which they are justified. For proceduralist theories, a moral claim is authoritative if and only if it is justified by good reasoning. Discourse ethics offers a methodological account of good reasoning and an epistemological account of why it is good. 
Proponents of discourse ethics share the Kantian epistemological belief that impartiality is a necessary condition of moral rationality and the methodological belief that the impartiality of proposed normative recommendations can only be determined via an unforced consensus among all those affected. Habermas writes, "True impartiality pertains only to that standpoint from which one can generalize precisely those norms that can count on universal assent because they perceptibly embody an interest common to all affected. It is these norms that deserve intersubjective recognition. Thus the impartiality of judgment is expressed in a principle that constrains all affected to adopt the perspectives of all others in the balancing of interests" (1990, 65; emphasis in original). Discourse theorists believe that justification in morality, as in science, requires a rational intersubjective consensus within the relevant community. Their theory, however, is distinguished from other Kantian theories by its insistence that moral agreements cannot be validated through philosophical thought experiments but instead require real-world discourse. Much of the discourse-ethics literature focuses on explaining the idea of rational consensus. Briefly, discourse theorists regard moral claims as justified only if the process of argumentation from which they emerge conforms to certain rules designed to capture the conditions of "a speech situation immune to repression and inequality" and to rule out all "external or internal coercion other than the force of the better argument" (Habermas $\underline{1990}$, 88-89). .6 Habermas contends that these rules are not mere conventions. Instead, they express the "unavoidable" or universal and necessary presuppositions of argumentative speech $(1990,81)$. Denying them while asserting moral convictions leads to a performative contradiction; the rules are presupposed by the idea of being convinced (1990, 90-91).

Habermas is well aware that the conditions for a speech situation immune to repression and inequality will never be fully met in the real world $(1990,88)$. In real life, he observes, we must be satisfied with an "approximation adequate enough for the purpose of argumentation" (1990, 91-92). He believes, however, that the conditions can be approximated closely enough to avoid moral skepticism. Just as scientific conclusions may be objective despite being based on evidence that is fallible, so moral conclusions may be valid even though the reasoning used to support them is always contestable.

The four conditions that we use to assess the model of moral justification offered by discourse ethics are not external or alien to this account of moral justification. The principled commitments of discourse ethics to impartiality, equality, and nonrepression all support the ideas that justificatory strategies should be plausible, usable, nonabusive, and practically feasible. Yet despite the overtly egalitarian and anti-authoritarian commitments of discourse ethics, we argue that its recommended model of moral justification may often fail these conditions when it is used in circumstances of diversity and inequality. Our argument examines how discourse ethics delineates the moral domain, characterizes moral agency, defines moral reasoning, and recommends courses of action.

\subsection{How Discourse Ethics Delineates the Moral Domain}

First note: discourse ethics is designed for addressing only a limited range of what are ordinarily thought to be moral questions. These are questions of justice, which discourse ethics identifies as issues that can be universalized. Only universalizable claims are thought able to be extracted from their specific cultural contexts and to be possible objects of transcultural consensus, so only these can claim to be morally rational. Habermas writes: "[T]he universalization principle acts like a knife that makes razor-sharp cuts between evaluative statements and strictly normative ones, between the good and the just. While cultural values may imply a claim to intersubjective acceptance, they are so inextricably intertwined with 
the totality of a particular form of life that they cannot be said to claim normative validity in the strict sense" $(1990,104)$. By contrast, questions of the good life are said to belong to "ethics" because they can be understood only in specific cultural contexts. These questions "have the advantage of being answerable within the horizon of lifeworld certainties," that is, within the specific cultural contexts from which they emerged $(1990,178)$. They are not susceptible to transcultural consensus, however, and so agreements about them cannot claim objective or universal validity.

Although discourse ethics delineates the moral domain in a way that appears conspicuously culture neutral, in practice this delineation systematically favors those cultures with more prestige and power in the current global order. This is because ideas and values that feature in dominant interpretations of the world are more likely to appear universal and culturally neutral than ideas and values used by the members of subordinated cultures, which are likely to appear particular and idiosyncratic. The point can be illustrated by the example of poverty. To many Westerners, this concept appears to have a universal meaning that is paradigmatically suited for justice analyses, but in fact poverty is understood differently across the world and takes its meaning from particular cultural contexts. Although Westerners typically define poverty in terms of access to material resources (or the money to purchase these), people elsewhere may define it in terms of access to physical security, leisure time, or particular communities or places; for instance, some Australian indigenous people regard themselves as poor if they lack kin relationships (Hunt 2010). What people take poverty to be depends on their conceptions of the good life.

The example of poverty illustrates how, in a context of global diversity and inequality, the insistence that morality is universal and culture neutral, while ethics is local and culture saturated, lends itself to abuses of power. It is easy to see how monetary definitions of poverty, which are widely accepted and appear to many as culturally neutral, are likely to be privileged as expressing poverty's real meaning. "Money makes the world go round." To the powerful, a monetary conception of poverty is likely to seem selfevidently "universalizable," and this allows them to dismiss other conceptions either as misunderstandings or as mere cultural preferences. It then becomes plausible that many people in nonWestern cultures are "really" poor, even if they do not recognize this.

Poverty is a stigmatizing term. The mere ascription of poverty can be abusive when it disregards the value of the wealth that supposedly poor people take themselves to possess. 7 In addition, ascriptions of poverty can become a rationale for abusive interventions touted as lifting out of poverty those designated as poor. This is precisely what happened in the last half of the twentieth century. After World War II, many non-Western countries were judged to be poor on the basis of their low gross domestic product, and this characterization was used to justify radical attempts to "develop" these countries, destroying environments and sustainable ways of life while creating enormously profitable "development industries" and a huge transfer of wealth from (now) poor to (now) much richer countries.

We certainly do not wish to blame discourse ethics for all the harms perpetrated by global economic development projects. Nevertheless, it is easy to see how such harms may be rationalized by a conception of moral justification that depends on universalizability. When concepts like poverty are interpreted in a way that is presented as culturally neutral even though it is culturally specific, this conceals the fact that the values of a more powerful culture are being legitimated at the expense of the values of a culture that is less powerful. The same point could equally well be made using many other 
examples, such as health, wealth, progress, development, and even culture itself. By definition, dominant understandings of crucial moral terms are more likely to prevail, while the understandings of less powerful cultures are more likely to be seen as mere local preferences, incapable of objective validity.

We contend that it is a philosophical mistake to suppose that any moral concepts, including justice concepts, can be excised from the cultural contexts that give them meaning and interpreted in a way that is culturally neutral. In situations of diversity and inequality, attempts to identify values in ways that are culturally neutral will always privilege the interpretations preferred by the culture that is more powerful in those situations. The cultural specificity of the dominant interpretations often will be hard to see, however, because the more powerful culture appears as the normal background of life. In contexts of diversity and inequality, claims of universalizability and cultural neutrality tend to conceal injustice rather than reveal it. - Thus it is a philosophical mistake not only to suppose that questions of morality can be distinguished sharply from questions of ethics. In contexts of diversity and inequality, it is a philosophical mistake that lends itself to rationalizing cultural repression.

\subsection{How Discourse Ethics Characterizes Moral Agents}

For discourse ethics, those agents who have standing to participate in justificatory processes are all those affected by the issue in question. In order to count as participating, however, they must reason in the way prescribed by discourse ethics. Habermas says that problems must be "stylized" "into questions of justice, in order to render practical questions accessible to cognitive processing by way of this abstraction" (Habermas 1982, 246; emphasis in original; qtd. Benhabib 1992, 72). This means that participants must present their considerations in universalizable form and that their responses must also take this form. Nonuniversalizable considerations cannot be objects of rational consensus and so may be legitimately disregarded.

Even though discourse ethics is nominally egalitarian and neutral toward all cultures, its conception of moral agency can rationalize marginalizing some members of some cultural groups. In order to be regarded as full moral agents, some people must, in effect, divest themselves of parts of their specific cultural identities. Their local or religious values may be precluded from having moral weight, and if people insist on invoking these values their own status as moral agents may come into question. For discourse ethics, people who insist on invoking religious or cultural values will at best be demoted to moral informants or witnesses, who may have reasons or a viewpoint to contribute, but whose reasons must be translated or stylized into universalizable form by bona fide moral agents, those who can divest themselves of specific cultural or religious identities. At worst, people who refuse to abandon their religious or cultural values may be demoted to the status of objects of moral concern, potential targets of paternalistic intervention or reeducation allegedly designed to help them develop full moral agency. Many projects for "educating" colonized and indigenous people have used precisely this rationale. Thus even though discourse ethics supposedly recognizes the agency of people in all cultures, it actually recognizes only agency expressed in a form that is culturally specific. Again, a seemingly abstract philosophical thesis about agency can lend itself to rationalizing repression.

\subsection{The Method of Moral Reasoning Prescribed by Discourse Ethics}

The reasoning method prescribed by discourse ethics is "a search for truth organized in the form of a competition" (Habermas 1990, 87). The competition is constrained by what Habermas regards as a few unavoidable rules of criticism. These include minimal rules of consistency, such as that speakers may not 
contradict themselves and that different speakers may not use the same expression with different meanings, and they also include the requirement that speakers be truthful and accountable in the sense of providing reasons for their views. The discursive competition must be open to all affected by the possible outcome, at least all those "with the competence to speak and act," and all are formally equal to introduce and question any assertions. All participants may question others' assertions, introduce their own assertions, and express their own attitudes, desires, and needs. No internal or external coercion may exist $(1990,88-89)$. Habermas notes that, in the real world, additional institutional measures are likely to be needed to enable approximation of the ideal speech situation. 9 We have several concerns about this proposed method of moral reasoning.

Our first concern is that the requirement of formally equal participation a priori rules out as irrational some ways of intersubjectively exchanging reasons. For example, it rules out the epistemic hierarchies of some communities, such as elder wisdom and the moral hierarchy of some religions. This begs the question of whether alternative reasoning strategies may be more rational in some contexts.

Our second concern focuses on the assumption of discourse ethics that formal equality enables all individuals to participate equally. This problem has been discussed extensively in the feminist literature exploring women's domination in discourse. One well-known example is Gayatri Chakravorty Spivak's essay "Can the Subaltern Speak?” (Spivak 1988). In this essay, Spivak argues that "subaltern" Third World women are represented in discourse in ways that obscure their subjectivity while promoting the interests of the authors of the texts. For instance, Indian widows immolated on their husbands' funeral pyres in the practice of sati were represented by British colonizers as victims who had to be saved from the slaughter of "backward practices" and by Indian men as heroes. Spivak famously asserts that the subaltern remains mute because she "cannot know or speak the text of female exploitation" (1988, 288).

Why is the subaltern unable to speak of her exploitation? Perhaps her indigenous language is incomprehensible to intellectuals and she cannot produce "texts" because she is illiterate. But why can't she even know about her exploitation? Even if she is unfamiliar with classic texts, surely she must be aware that something is wrong with her situation? Uma Narayan suggests an answer to this puzzle. She writes that certain kinds of oppressive contexts render people unable to conceptualize the injustice to which they are subject. For instance, many girls of her grandmother's generation saw themselves as personally unfortunate, but they did not locate the causes of their misery in larger social arrangements (Narayan 1989, 267-68). Narayan suggests that the subaltern's muteness is rooted in her lack of a vocabulary for articulating her injuries and aspirations, and Narayan's diagnosis also implies an appropriate remedy: the subaltern needs a more adequate moral vocabulary. Spivak, however, contends that no such vocabulary is available. Even supposedly critical vocabularies, such as Marxist structuralism and poststructuralism, obscure the distinctive nature of the subaltern woman's oppression, leaving her still mute. $\frac{10}{}$

Language is a public construct, and its absence is a public, not a private, deficit. Creating a new language is in principle a collective project, not something that can be accomplished by a single individual. If the subaltern were to enter moral discourse as a lone individual, she would be able to communicate only by using the dominant language, and her experience would remain distorted and repressed. She can break her silence only by collaborating with others in similar situations to develop a public language able to express their common experiences. Only by developing a collective identity distinct from her individual 
identity as the particular daughter, wife, and mother of particular others can the subaltern even come to see herself as subaltern. And only in this way can she break through the barriers to her knowledge and speech.

The difficulty of developing new vocabularies in the kind of formally open and competitive discourse prescribed by discourse ethics is well established. $\stackrel{11}{=}$ We think that, in present-day contexts of diversity and inequality, the insistence of discourse ethics that only such reasoning strategies are morally rational allows for the abuse of cultural power.

Our third and related concern about the reasoning method recommended by discourse ethics is that it fails to notice that hearing others speak is an enterprise in which people may succeed, fail, or be partially successful. Discourse ethics conceptualizes rational discourse in terms of reversibility or the ability to take the point of view of others, but the concept of reversibility is problematic. AfricanAmerican philosopher Laurence Thomas writes that a privileged person who has experienced occasional hardships and humiliations does not thereby know what it is like to be subjected to the systematic devaluation that constitutes informal racism any more than hanging upside down with closed eyes will tell him what it is like to be a bat. Moreover, he argues it would be morally presumptuous to assume that one can know. "If one encounters a Holocaust survivor, it would be moral hubris of the worst sortunless one is also such a survivor - to assume that by way of rational imaginative role-taking ... one could even begin to grasp the depth of that person's experiences - the hurts, pains, and anxieties of that individual's life. There is not enough good will in the world to make it possible for persons (who are not Holocaust survivors) to put themselves imaginatively in the mind of a Holocaust survivor" (Thomas 1992-93, 234).

Iris Young agrees that is often disrespectful and presumptuous to think that we can imaginatively adopt other people's standpoints. Doing so assumes that other people are similar to us without acknowledging their differences. This belief is politically as well as morally dubious, because privileged people who try to put themselves in the position of those who are less privileged are likely to rely on projections and fantasies (Young 1997, 48). For instance, they may see the less privileged as leading a simple idyllic existence or as utterly miserable. In light of these considerations, we think that the prescription of discourse ethics to adopt the perspective of others is at best naïve, overlooking the structural obstacles to discourse that are created by cultural diversity and systematic inequalities of power.

Habermas does not intend his model of domination-free discourse to serve as a blueprint from which real-world moral argumentation may never deviate. Instead, he intends it as a philosophical ideal guiding the design of "institutional measures" capable of "neutraliz(ing) empirical limitations" in the real world. Because the ideal of domination-free discourse is posed at a high level of philosophical abstraction, it could be interpreted as allowing a variety of deviations from formal equality, including even temporarily closed discourse communities as institutional measures to avoid "external interference." We might conclude that this model of moral reasoning is basically correct but, because it is abstract, necessarily limited in its ability to provide concrete guidance for practical reasoning in realworld contexts.

Our main concern is not that the model of good moral reasoning in discourse ethics is abstract and consequently indeterminate. Instead, we question the adequacy of an epistemological model that regards moral rationality as best exemplified by a discursive competition among equivalently situated individuals, paying no theoretical attention to cultural as well as individual diversity and systematic as 
well as individual inequality. Systematic diversity and inequality are ubiquitous. They are not anomalous but rather endemic to the human condition as we know it. For this reason, we think they should be addressed at the center of even an abstract account of moral reasoning, not left for the level of application. In existing contexts of diversity and inequality, it is unlikely to be rational to rely on moralreasoning strategies that fail to build in safeguards against repression and abuse, even though such safeguards will never be infallible. Moral reasoning that ignores systematic cultural and social variations in moral points of view is likely to permit or even legitimate the repression of "nonmainstream" moral perspectives and vocabularies and to fail to facilitate the emergence of new ones. The disregard of discourse ethics for the epistemological implications of cultural diversity and social inequality leads it to postulate a model of moral reasoning that fails to recognize the collective as well as individual dimensions of moral agency and to overemphasize the competitive aspects of moral reasoning at the expense of the cooperative aspects, which arguably are more fundamental.

\subsection{Likely Courses of Action Justified by Discourse Ethics}

Discourse ethics insists that it offers no more than an abstract model of moral reasoning, so that actionguiding prescriptions emerge only from using this model on specific occasions. For this reason, we might suppose that discourse ethics offers no concrete guidance for action that we can assess outside its use in a particular context of dispute. However, the restriction by discourse ethics of moral reasoning to exclude many "cultural" aspects of the good life has practical implications that are worth considering.

The term "culture" is capable of many interpretations. Earlier in this article, in suggesting that the cultural specificity of interpretations of moral concepts is often overlooked, we pointed toward a broad construal of "culture" as pervading most if not all aspects of social life. In the context of contemporary political philosophy, however, including the so-called multiculturalism debate, "culture" is usually interpreted more narrowly to contrast with politics and the economy. For example, Nancy Fraser contrasts concerns about cultural recognition with concerns about economic redistribution (Fraser 1997). Susan Okin writes, "[T] he sphere of personal, sexual, and reproductive life provides a central focus of most cultures. ... Religious or cultural groups are often particularly concerned with 'personal law'-the laws of marriage, divorce, child custody, division and control of family property, and inheritance" $(\underline{1999}, 12-13)$. When "culture" is construed in this narrower way, it has special significance for the members of minority cultures and, as is often noted, for women everywhere. Because culture in the narrower sense is often seen as a source of women's oppression, The Beijing Declaration and Platform for Action states, "Any harmful aspect of certain traditional, customary or modern practices that violates the rights of women should be prohibited and eliminated" (United Nations 1995, point 224).

Discourse theorists confront a dilemma. If they accept the narrow understanding of culture usual in contemporary political philosophy, it follows that discourse ethics is unable to provide guidance on many normative issues that have special importance for those who are typically more vulnerable, namely, women and the members of minority cultures. On the other hand, if discourse theorists decide to enlarge the domain of morality so that it includes some hitherto excluded issues, then it seems inevitable that local values will be trumped by values regarded as universal, such as human rights. It appears likely that the members of more marginalized or vulnerable cultures, perhaps characterized as "traditional" or even "simple," "backward," or "exotic," may be asked to abandon what they regard as central aspects of their identities and lives. 


\subsection{Summing Up Our Assessment of Discourse Ethics}

In this section, we draw on our four assessment conditions to evaluate the reliability of the model of moral justification recommended by discourse ethics. Although there are surely situations in which this strategy works well, we conclude that, in situations of diversity and inequality, it consistently tends to deliver dubious or untrustworthy conclusions.

\subsubsection{Plausibility}

First, we consider the plausibility of the metastory told by discourse ethics. In a classic example of aprioristic moral epistemology conducted from the armchair, Habermas asserts that the conditions of formal equality express the universal and necessary presuppositions of argumentative speech or the concept of being convinced. Many modern Western philosophers, especially contractarians and neoKantians, would certainly agree that this type of reasoning is precisely what is required to convince them. Such a story is also likely to be plausible to members of the juridical administrative classes in modern societies; indeed, something like it is presupposed by most modern legal systems and bureaucracies. The story is not plausible, however, to members of hierarchical moral communities, in which some members are regarded as having superior moral knowledge. It is also unlikely to convince the more vulnerable members of nominally egalitarian communities, who may have suffered intimidation or silencing in situations where they have formally had their say, such as law courts or formal hearings. The reasoning model that discourse ethics recommends for moral justification is not equally plausible to all groups, and, in the present world order, it is more likely to appear fair and unbiased to those occupying more privileged positions in more powerful cultures.

\subsubsection{Usability}

Is the model of moral justification found in discourse ethics equally usable by all? At first sight, it is hard to imagine a prescriptive model that could be more open and egalitarian. We have seen, however, that the insistence by discourse ethics on using a supposedly neutral and universalizable vocabulary is based on a philosophical mistake that in practice allows members of the dominant culture to conduct moral discussion in their terms. It allows the dominant vocabulary to go unmarked as culturally specific and legitimates the moral perspective that this vocabulary embodies. More generally, the requirement by discourse ethics that religion and culture be bracketed advantages people who do not consider their religion as central to their lives and do not regard themselves as belonging to any specific culture. People for whom religion and culture are central may find this strategy rationally disabling and their views in effect excluded from discourse.

\subsubsection{Nonabusiveness}

Does the model of moral justification offered by discourse ethics permit the abuse of power? In our view, fairness and truth are unlikely to be promoted by a practice of reasoning that ignores pervasive cultural diversity and social inequality. Although Habermas pays lip service to the need for institutional mechanisms to counteract inequality, he gives no theoretical attention to the ways in which, in the real world, those who have more cultural and social power are likely to exert disproportionate influence in deciding how to interpret and use the prescriptive model of discourse ethics. His theory disregards the facts that the powerful will have disproportionate influence in deciding: what is on the moral agenda; how the issues should be framed; who is counted as a participant with interests at stake; how participants' contributions should be formulated; what is seen as legitimate evidence and argument; 
which inequalities are determined to be minor enough to be disregarded; when sufficient time for consensus has passed; and when the discussion is over.

\subsubsection{Practical Feasibility}

Does the model for moral justification presented by discourse ethics tend to justify recommendations for action that are feasible alternatives for those involved? This question cannot be answered conclusively in the abstract, without seeing how the strategy works in the context of a particular dispute. We do know, however, that discourse ethics is unable, on its own admission, to address many issues that it defines as "cultural" or ethical, and we also know that these are precisely the issues that often have disproportionate importance to the lives of those who are more vulnerable. Moreover, since the strategy tends to provide more privileged groups with an unfair advantage in justifying their views, it seems reasonable to speculate that, when this strategy is used in circumstances of diversity and inequality, it is unlikely to support courses of action that are equally feasible for everyone.

\section{The Fundamental Problem: Three Layers of Invidious Idealization}

\subsection{What Is Idealization?}

"Idealization" is a term with many possible meanings, not only outside philosophy but also increasingly within it.. We use "idealization" in the sense explained by Onora O'Neill, who writes, "An assumption, and derivatively a theory, idealizes when it ascribes predicates-often seen as enhanced, 'ideal' predicates - that are false of the case in hand, and so denies predicates that are true of that case. For example, if human beings are assumed to have capacities and capabilities for rational choice or selfsufficiency or independence from others that are evidently not achieved by many or even by any actual human beings, the result is not mere abstraction; it is idealization" $(1996,41) . \underline{13}$

O'Neill notes that idealizations can be theoretically useful but warns that they are also dangerous. She writes, "[W]e learn something interesting about economic behaviour by considering 'idealized' consumers and 'perfect' markets. But if as economic actors we assume that consumers and markets live up to these idealizing fictions we will fail to adjust our action to actual circumstances, and may pay, or exact, a heavy price. Practical reasoning that assumes that 'ideal' predicates are satisfied will not reach conclusions safely and soundly for cases where they are not satisfied" $(1996,41)$. We agree with O'Neill that idealization can be useful and even indispensable for philosophers, who aim to provide general accounts of the fundamental features of our world and lives. In order to avoid inessential details, philosophers (and other theorists) often need to make simplifying and even counterfactual assumptions. Some philosophical idealizations are not harmless, however; instead, they are invidious or philosophically damaging. Below we explain why the harmfulness of the model of moral justification in discourse ethics stems from its invidious idealization of domination-free discourse. In the following section, we contend that the broader metaphilosophical conception of the mission and method of moral epistemology that discourse ethics assumes is also (and not coincidentally) invidiously idealized.

\subsection{The Model of Moral Justification Offered by Discourse Ethics Is Invidiously Idealized}

The model of moral justification recommended by discourse ethics brackets or imagines away diversity and inequality. We have seen how this occurs in the exclusion by discourse ethics of many topics and considerations from the realm of possible moral assessment, in the ways it limits the expression of 
moral agency, and in its failure to envision safeguards for cultural difference and social inequality. Bracketing or imagining away diversity and inequality may well be safe for some philosophical purposes, but it is surely unsafe when seeking to develop an account of moral justification for use in a world pervaded by diversity and inequality.

In a world of diversity and inequality, the model of moral justification recommended by discourse ethics tends systematically to favor the moral perspectives of people with more privilege and power. For this reason, discourse ethics is unlikely to provide an adequate reasoning strategy for fairly resolving disputes among people who hold diverse religious and cultural views and/or who are unequally situated. The interpretations by discourse ethics of the moral domain, of moral agency, and of moral reasoning purport to be universal or culturally neutral, but we have seen that in fact they are not only culturally specific but also specific to the cultures that currently wield most power in the global context. Discourse ethics advocates a model of moral justification that lends itself to justifying the abuse of social power both in process and in outcome. Moreover, by insisting that authoritative claims can be produced only through reasoning according to this model, discourse ethics disguises partiality as impartiality and opens the way for philosophy itself to be used as a tool of repression.

Our criticisms of discourse ethics do not mean that we reject the ideal of domination-free discourse; to the contrary, commitment to this ideal is implicit in our conditions for assessing models and practices of justification. We dispute, however, the idea that a single privileged prescriptive model for achieving domination-free discourse can be imagined independently of specific contexts. In some contexts, we think that domination-free discourse will look very different from the formally open and competitive procedures imagined by discourse ethics. Whether, where, and how to engage in discursive justification must be decided in a power-aware way in particular contexts, always with an eye to new forms of exclusion and power abuse.

\subsection{Discourse Ethics Assumes a Misleadingly Idealized Conception of the Mission of Moral Epistemology}

Justification is a social process. It consists in giving accounts and exchanging reasons. A moral conclusion is not justified simply in virtue of the fact that the persons arriving at the conclusion have correctly identified an action or practice as morally wrong, even when they have presented what they regard as good reasons for their conclusion. The conclusion is justified by the account that is given to others about why the action is wrong, by the argumentation and reasons offered, and by others' responsive uptake of that account. Discourse ethics recognizes that justification is achieved through the intersubjective exchange of reasons, and it insists on the indispensability of actual as opposed to imagined discourse. For this reason, we think that even though the account of moral justification by discourse ethics is still flawed in the way we diagnose, it is less idealized than those offered by many other neo-Kantian theories. Nevertheless, we argue in this section that discourse ethics, like many other philosophical theories, assumes a general conception of moral justification that is also invidiously idealized because it fails to take seriously a vital implication of its insistence that moral justification occurs in actual intersubjective exchanges. This implication is that moral justification, precisely because it is social, is also always situated.

Moral justification always occurs (or fails) in particular contexts. The need for justification arises when a particular action or social practice faces a particular challenge and must be justified to a particular individual or group of people. This means that practices for justification must be tailored to the situation 
at hand. Even though occasions of successful justification must always meet the conditions of plausibility, usability, nonabusiveness, and practical feasibility, the ways in which those conditions are fulfilled will vary according to the context. The same strategies of justification may be plausible, usable, nonabusive, and practically feasible in one context and fail some or all of those conditions in another. Plausibility and intelligibility are obviously relative to particular addressees, and who are the relevant addressees depends on the particular dispute in question. Which strategies are usable and practically feasible also depends on the particular situation. Therefore, in moral reasoning across communities, the appropriate moral vocabulary and forms of reasoning cannot be assumed but instead must be negotiated and perhaps invented.

Does this situated conception of moral justification result in moral subjectivism or relativism? If some people accept the justifications offered for a particular action or practice and some won't or can't accept them, does this mean that the same action or practice may be morally permissible for some people but impermissible for others? In this regard, moral justification is no different from scientific justification.

Just as not everyone accepts the arguments for the view that slavery is wrong, so not everyone accepts the scientific justifications provided for the view that the earth is not flat. We think that both these claims are certainly true because they are supported by the best reasons available to the moral and scientific communities to which we belong. We recognize, however, that the members of some communities continue to doubt and that these skeptics can be persuaded only if they are presented with evidence and arguments that, in context, meet their conditions of plausibility, usability, nonabusiveness, and feasibility. It begs the question to insist that only our reasons are good; those with whom we are disputing must also recognize them as good. $\stackrel{14}{ }$ As O'Neill says, "Since practical reasoning has many audiences, some more restricted and others more inclusive, it may and indeed must on different occasions rely on more abstract and on more specific views of the characteristics of those audiences" $(1996,61)$. No claims are justified in general, for all time, or sub specie aeternitatis. The claims that slavery is wrong and that the earth is not flat are extremely unlikely to be defeated, since denying them would mean rejecting extremely extensive networks of established moral and scientific belief. Nevertheless, even these beliefs are defeasible in principle, if we are willing to change enough of our other beliefs (Quine 1951). Even the most considered convictions are fixed only provisionally, and if they are not to be held dogmatically they must remain open to rethinking as new insights or evidence or means of argumentation become available. Once this is recognized and moral justification is understood as a collection of practices that are always socially situated, it becomes clear that no single model or practice of moral justification can be expected to work in all contexts. Moral authority does not emerge from the use of some supermodel. Instead, it emerges from a good fit between specific reasoning strategies and the social contexts in which they are used. Our conditions are designed to assess this fit. To pursue an all-purpose supermodel is to idealize invidiously the nature of moral justification and the mission of moral epistemology.

\subsection{Abandoning the Search for the Philosopher's Stone and Rethinking the Mission of Moral Epistemology \\ Medieval philosophers sought the so-called philosopher's stone that would convert base metals into gold. Similarly, many contemporary philosophers seek a single privileged model of moral argumentation that will enable its users to turn base and fallacious everyday reasoning into a gold standard of rational argumentation. We have argued that this search rests on a philosophical superstition, an invidiously}


idealized conception of the philosopher's mission that is not only misleading but also morally and politically dangerous.

If moral epistemology is no longer taken to be the search for a uniquely privileged model of moral reasoning that leads to a single authoritative moral point of view, how might its mission be reconceptualized? We propose that moral epistemology should seek to develop a variety of epistemological models useful for guiding practices of moral reasoning in differing social contexts, together with guidelines explaining the types of situations where the practices prescribed by the models are likely to work well because they meet our conditions of adequacy. We suggest that these models be regarded as exemplars of moral justification.

Once the mission of moral epistemology is rethought, its method must be rethought as well. Because all moral knowledge is situated and there can be no uniquely privileged moral point of view, moral justification does not begin at a single designated starting point, end at a single finishing point, or proceed by a single best route. We need multiple maps for multiple journeys. It is not plausible that multiple maps for many journeys, some still unplanned, can be drawn successfully by solitary philosophers sitting alone in their armchairs. In our companion article, we explain our alternative naturalized conception of the method of moral epistemology, which requires both moral teamwork and moral fieldwork.

\section{Acknowledgments}

We much appreciate the comments of our audience when this article was given as the annual Metaphilosophy Lecture at Stony Brook University, State University of New York, in March 2013. Our larger project has been supported by the University of Oslo's Center for the Study of Mind in Nature, where we have worked together for a month in each of four years, 2009-2012. We are immensely grateful for the opportunity to develop our ideas in such a philosophically rich environment.

\section{Footnotes}

1 http://www.upi.com/Top News/World-News/2011/03/04/Frances-veil-ban-effective-in-April/UPI71011299247319/\#ixzz1FqAsqNfu (accessed 6 March 2011); http://www.bbc.co.uk/news/world-europe-14261921 (accessed 23 July 2011).

2 http://www.believermag.com/issues/200303/?read=interview strawson (last accessed 30 April 2013). 3 The adequacy conditions that we propose contain obviously normative elements, but we regard normative constraints as logically appropriate for moral rationality in the same way that empirical adequacy is a logically appropriate constraint on scientific rationality. Science seeks to determine how the world actually is, so it is appropriately constrained by empirical adequacy; morality seeks to determine how the world should be, so is appropriately subject to normative constraints.

4 We do not assert that our conditions provide a full account of moral justification. Even if substantive normative claims are supported by arguments that meet all of our conditions, it is possible that further conditions might have to be met in order for the claims to be fully justified or authoritative.

5 We recognize that the language of power abuse is more unusual in philosophy than the language of equality, freedom, and community but we find that this language is well suited for our purposes, which include identifying ways in which members of more powerful groups have utilized 
seemingly neutral reasoning strategies to rationalize their own agendas. Although we endorse the broad values of freedom, equality, and community, we want to mark our distance from some customary interpretations of them, particularly interpretations that dismiss the possibility that hierarchies might sometimes have moral or epistemic worth.

6 In earlier work, Habermas spoke of the rules as defining an ideal speech situation but later came to prefer the terminology of an "unrestricted communication community" (die ideale Kommunicationsgemeinschaft) $(1990,88)$. He also sometimes speaks of constraint-free or domination-free communication.

7 Elisabeth Furst-L'Orange recalls: "I particularly remember one woman, as I talked about Moldova as a severely poor country. 'Don't say we're poor,' she begged me. Well, this is a fact, I responded. 'But we are so much more! Think about our lovely countryside, think about our rich culture, our food and wine!'” (Furst-L'Orange 2010).

8 In a similar spirit, Helen Longino has argued compellingly that the aspiration to identify a politically and morally neutral method for selecting politically unbiased theories in science is misguided because there is no neutral "view" that can be discerned independently of context. No science is value free, and the ideal of value-free science is a dangerous idealization because it hides the often pernicious operations of political and social power in the practice of science under the pretense of "scientific objectivity." As Longino puts it, "We should worry more about the concealing of political agendas behind the mantle of scientific neutrality than about the consequences of abandoning the illusion of neutral arbiters of our cognitive practices" (1990, 55).

9 Habermas recognizes that real-world "discourses take place in particular social contexts and are subject to the limitations of time and space. Their participants are not Kant's intelligible characters but real human beings driven by other motives in addition to the one permitted motive of the search for truth. ... Because of all these factors, institutional measures are needed to sufficiently neutralize empirical limitations and avoidable internal and external interference so that the idealized conditions always already presupposed by participants in argumentation can at least be adequately approximated." Particular "conventions that help to actualize the ideal content of the presuppositions of argumentation under empirical conditions" must be differentiated from the rules of discourse, to avoid the fallacy of misplaced concreteness (1990, 93).

10 In speaking of cases when no conceptual resources are yet available for members of oppressed social groups to make their experiences of oppression intelligible, even to themselves, Miranda Fricker uses the term "hermeneutical injustice." She regards such hermeneutical gaps as unjust when oppressive social relations are partially responsible for the epistemic deficiency, for example, when oppressive gender norms operate to keep women isolated from one another and excluded from public life, so that they are prevented from collective discourse through which new vocabularies are developed (Fricker 2007, 147-75).

11 The history of science is full of accounts of "invisible colleges" or groups of scientists working from shared assumptions, which David L. Hull calls "demes" (1988, 433-34). Artists have often worked in "schools," and philosophers in "circles." Nancy Fraser argues that repressed groups form "subaltern counterpublics" that are "parallel discursive arenas where members of subordinated social groups invent and circulate counterdiscourses to formulate oppositional interpretations of their identities, interests, and needs" $(1990,67)$. Jaggar argues that small 
communities, whose members are known personally to each other, have been indispensable to the development of Western feminist perspectives, allowing members to develop a distinct moral vocabulary that offers alternative understandings of social phenomena (Jaggar 2000).

12 For instance, a vigorous debate is currently under way concerning the usefulness of Rawlsian ideal theory as a methodological approach in political philosophy.

13 O'Neill is very concerned to distinguish between idealization and abstraction, which she defines as "a matter of bracketing, but not of denying, predicates that are true of the matter under discussion" $(\underline{1996}, 40)$. We think that O'Neill and philosophers following her lead may have overblown the importance of this distinction. Bracketing or ignoring predicates such as diversity and inequality may be logically distinct from explicitly denying their existence, but in many cases the difference does not seem to us substantial. Bracketing or ignoring diversity and inequality may still be misleading and philosophically dangerous by directing philosophical attention away from areas where it should focus. However, whether or not O'Neill's distinction between abstraction and idealization is worth maintaining does not affect our present argument.

14 Of course, the skeptics' reasoning itself can be evaluated by the adequacy conditions we propose. To the extent that people have not completely removed themselves from social life and have to account to other people for their beliefs, then they too must offer argumentation and reasoning that are plausible, usable, nonabusive, and feasible.

\section{References}

Benhabib, Seyla. 1992. Situating the Self: Gender, Community and Postmodernism in Contemporary Ethics. London: Routledge.

Fricker, Miranda. 2007. Epistemic Injustice: Power and the Ethics of Knowing. Oxford: Oxford University Press.

Fraser, Nancy. 1997. "From Redistribution to Recognition? Dilemmas of Justice in a 'Postsocialist' Age." In Justice Interruptus: Critical Reflections on the "Postsocialist" Condition, 11-39. New York: Routledge.

Furst-L'Orange, Elisabeth. 2010. "The Feminization of Poverty: The Case of Moldova." Talk at Oslo Litteraturhuset, 15 June.

Habermas, Jürgen. 1982. "A Reply to My Critics." In Habermas: Critical Debates, edited by John B. Thompson and David Held, 219-283. Cambridge, Mass.: MIT Press.

Habermas, Jürgen. 1990. "Discourse Ethics: Notes on a Program of Philosophical Justification." In Moral Consciousness and Communicative Action, translated by Christian Lenhardt and Shierry Weber Nicholsen, 43-115. Cambridge, Mass.: MIT Press.

Hull, David L. 1988. Science as a Process: An Evolutionary Account of the Social and Conceptual Development of Science. Chicago: University of Chicago Press.

Hunt, Janet. 2010. "Assessing Poverty, Gender and Well-Being in 'Northern' Indigenous Communities." In International Handbook of Gender and Poverty: Concepts, Research, Policy, edited by Sylvia Chant , 241-247. Cheltenham, U.K.: Edward Elgar.

Jaggar, Alison M. 2000. "Globalizing Feminist Ethics." In Decentering the Center: Philosophy for a Multicultural, Postcolonial, and Feminist World, edited by Uma Narayan and Sandra Harding , 125. Bloomington: Indiana University Press.

Longino, Helen E. 1990. Science as Social Knowledge: Values and Objectivity in Scientific Inquiry. Princeton: Princeton University Press. 
Narayan, Uma.1989. "The Project of Feminist Epistemology: Perspectives from a Nonwestern Feminist." In Gender/Body/Knowledge: Feminist Reconstructions of Being and Knowing, edited by Alison M. Jaggar and Susan R. Bordo , 256-269. New Brunswick, N.J.: Rutgers University Press.

Okin, Susan Moller. 1999. "Is Multiculturalism Bad for Women?" In Is Multiculturalism Bad for Women? edited by Joshua Cohen, Matthew Howard, and Martha C. Nussbaum , 9-24. Princeton: Princeton University Press.

O'Neill, Onora. 1996. Towards Justice and Virtue: A Constructive Account of Practical Reasoning. Cambridge: Cambridge University Press.

Quine, W. V. O. 1951. "Two Dogmas of Empiricism." Philosophical Review 60:20-43. (Also available in W. V. O. Quine, From a Logical Point of View [Cambridge, Mass.: Harvard University Press, 1953; second, revised edition 1961].)

Spivak, Gayatri Chakravorty. 1988. "Can the Subaltern Speak?" In Marxism and the Interpretation of Culture, edited by Cary Nelson and Lawrence Gross , 66-111. London: Macmillan.

Thomas, Lawrence. 1992-93. "Moral Deference." Philosophical Forum 14, nos. 1-3:233-250.

Young, Iris Marion. 1997. Intersecting Voices: Dilemmas of Gender, Political Philosophy, and Politics. Princeton: Princeton University Press.

United Nations. 1995. Beijing Declaration and Platform for Action: Report of the Fourth World Conference on Women, available at http://www.un.org/esa/gopher-data/conf/fwcw/off/a20.en (at art. 224) (last accessed 30 April 2013). 